\title{
Toxicity Assessment of Reference and Natural Freshwater Sediments with the LuminoTox Assay
}

\author{
P. M. Dellamatrice, ${ }^{1}$ R. T. R. Monteiro, ${ }^{1}$ C. Blaise,${ }^{2}$ J. L. Slabbert, ${ }^{3}$ F. Gagné, ${ }^{2}$ S. Alleau ${ }^{4}$ \\ ${ }^{1}$ Laboratório de Ecotoxicologia, Centro de Energia Nuclear na Agricultura, \\ Piracicaba-SP, Brazil \\ ${ }^{2}$ Centre Saint-Laurent, Environment Canada, 105 McGill, Montréal, Québec H2Y 2E7, Canada \\ ${ }^{3}$ Council for Scientific and Industrial Research, Environmentek, Pretoria 0001, South Africa \\ ${ }^{4}$ Université de Nantes, IUT de La Roche-sur-Yon, 85000 La Roche-sur-Yon, France
}

Received 17 June 2005; accepted 21 March 2006

\begin{abstract}
We examined the possibility of adapting the LuminoTox, a recently-commercialized bioanalytical testing procedure initially developed for aqueous samples, to assess the toxic potential of sediments. This portable fluorescent biosensor uses photosynthetic enzyme complexes (PECs) to rapidly measure photosynthetic efficiency. LuminoTox testing of 14 CRM (Certified Reference Material) sediments was first undertaken with (1) a "solid phase assay" (Lum-SPA) in which PECs are in intimate contact with sediment slurries for a 15 min exposure period and (2) an elutriate assay (Lum-ELU) in which PECs are exposed for $15 \mathrm{~min}$ to sediment water elutriates. CRM sediment toxicity data were then compared with those generated with the Microtox Solid Phase Assay (Mic-SPA). A significant correlation $(P<0.05)$ was shown to exist between Lum-SPA and Mic-SPA, indicating that both tests display a similar toxicity response pattern for CRM sediments having differing contaminant profiles. The sediment elutriate LumELU assay displayed toxicity responses (i.e. measurable $\mathrm{IC}_{20} \mathrm{~s}$ ) for eight of the $14 \mathrm{CRM}$ sediments, suggesting that it is capable of determining the presence of sediment contaminants that are readily soluble in an aqueous elutriate. Lum-SPA and Mic-SPA bioassays were further conducted on 12 natural freshwater sediments and their toxicity responses were more weakly, yet significantly, correlated. Finally, Lum-SPA testing undertaken with increasing mixtures of kaolin clay confirmed that its toxicity responses, in a manner similar to those reported for the Mic-SPA assay, are also subject to the influence of grain size. While further studies will be required to more fully understand the relationship between Lum-SPA assay responses and the physicochemical makeup of sediments (e.g., grain size, combined presence of natural and anthropogenic contaminants), these preliminary results suggest that LuminoTox testing could be a useful screen to assess the toxic potential of solid media. (C) 2006 Wiley Periodicals, Inc. Environ Toxicol 21: 395-402, 2006.

Keywords: freshwater sediments; toxicity; LuminoTox; solid phase assay; photosynthetic enzyme complexes; sediment grain size
\end{abstract}

\section{INTRODUCTION}

Sediment contamination by (in)organic chemicals released in aquatic systems from diverse types of (non)point sources

Correspondence to: C. Blaise; e-mail: christian.blaise@ec.gc.ca Published online in Wiley InterScience (www.interscience.wiley.com). DOI 10.1002/tox.20186 of pollution (urban, industrial, and agricultural) continues to be a crucial environmental issue. In the freshwater arena, biota can indeed be adversely affected by the resuspension of toxic sediments via both natural (e.g. flood scouring) and man-made (e.g., dredging, navigation, open water deposition) activities. Hence, management strategies invariably employ bioassays, along with chemical analysis, to appraise the toxic potential of contaminated sediments. This then 
leads to sound decision-making relating to sediment removal, disposal, or treatment based on considerations aimed at protecting aquatic species.

A fairly large number of bioassays can be used to measure the toxicity of sediment elutriates, pore waters, and extracts, but fewer are presently available to evaluate that of whole sediment where both readily-soluble and adsorbed toxicants may be present (Côté et al., 1998). Recommended whole sediment toxicity tests are usually performed with benthic organisms that measure growth and survival after 10 or 14 days of exposure (Borgmann et al., 2005; Péry et al., 2005). While these are undeniably useful and relevant bioassays, parallel research efforts have also focused on developing smaller-scale "direct contact" tests featuring shorter exposure times, as well as increased sample throughput and cost-effectiveness. Increasingly, such microscale assays are often used as prescreens to rapidly identify toxic sediment samples that can then be confirmed as such by the more traditional benthic organism tests. Of these so-called direct contact (or "solid phase") small-scale tests, all are exclusively conducted with bacteria (Kwan and Dutka, 1995; Bitton et al., 1996; Corbisier et al., 1996; Doe et al., 2005) or micro-algae (Blaise and Ménard, 1998; Adams and Stauber, 2004).

To augment solid media microscale testing possibilities, we examined the possibility of adapting the LuminoTox, a recently commercialized bioanalytical testing procedure initially developed for aqueous samples, to assess the toxic potential of sediments. The LuminoTox instrument is a portable fluorescent biosensor that uses photosynthetic enzyme complexes (PECs) to measure photosynthetic efficiency (Boucher et al., 2005; Environment Canada, 2005; LuminoTox, 2005). Intoxicated PECs yield markedly diminished photosynthetic efficiency over control PECs, thereby confirming the action of bioavailable contaminant(s). The LuminoTox analyzer thus offers a simple and rapid means of screening samples for the presence of toxicity. Herein, we report on the development of LuminoTox solid phase and elutriate assay procedures that were applied for testing (1) certified reference material (CRM) sediments and (2) natural freshwater sediments. The LuminoTox solid phase assay results were then compared with those generated with a well-standardized solid phase bacterial luminescence toxicity assay. The influence of sediment grain size on LuminoTox toxicity responses was also investigated.

\section{MATERIALS AND METHODS}

\section{Sediment Samples}

Two series of sediment samples were employed to generate toxicity data with the bioassay procedures described later. The first were certified reference materials (CRM) prepared by the National Water Research Institute (NWRI, Burling- ton, Ontario, Canada) comprising naturally-contaminated sediments originating from various locations in the Great Lakes basin (NWRI, 2000). These freeze-dried (ground to less than 200-mesh particle size) sediments have undergone chemical characterization for several PCB congeners, PAHs, chlorobenzenes, and a number of trace metals. We tested eight CRM sediments reported to be mostly contaminated with organics (EC-1 to EC-8) and six mainly contaminated with heavy metals (SUD-1, HR-1, TH-1, TH-2, WQB-1, and WQB-3). The second series of samples comprised 12 natural freshwater sediments reflecting mixed contamination and originated from the Saint-Lawrence River, Québec, Canada (M1 to M4), Lake Ontario, Ontario, Canada (B1 to B4), and the Berlin waterways (P1 to P4). These sediments were collected in spring-summer of 2003, homogenized/aliquoted in the laboratory, and quickly frozen $\left(-20^{\circ} \mathrm{C}\right)$ for subsequent analyses linked to a different project. Subsamples were thawed and used to compare LuminoTox and Microtox solid phase assay toxicity results for the present study.

Finally, to determine whether the LuminoTox solid phase assay toxicity responses could be influenced by sediment particle size, toxicity testing was undertaken with a mixture of silica sand (Allwhite Silica Sand, medium fine grade No. 0; Shaw Resources, Nova Scotia, Canada, www.shawresources.ca; grain size between 0.125 and $0.25 \mathrm{~mm}$ ) and kaolin clay (Fisher Scientific, catalogue No. K2-500, lot No. 9502120; grain size $<0.004 \mathrm{~mm}$ ). In this experiment, kaolin concentrations ranged from 0 to $100 \%$ sediment content.

\section{Toxicity Testing Procedures}

\section{Bacterial Luminescence Solid Phase Assay}

The Microtox solid phase assay (Mic-SPA) was performed to assess sediment toxicity by following the Environment Canada reference method (Environment Canada, 2002). The principle of the Mic-SPA is based on the fact that Vibrio fischeri, the luminescent marine bacterium employed in this assay, undergoes suppression of light output after short-term exposure to toxicants. Specific disposable polystyrene tubes $(15.5 \times 56 \mathrm{~mm}, 7.5 \mathrm{~mL}$ capacity, hemispherical bottom) and associated filter columns (Strategic Diagnostic Inc., catalogue No. AZF 686093) are required to undertake this assay. In brief, rehydrated bacteria placed in polystyrene tubes are directly exposed to a sediment sample (maximum dry/wet weight of $0.3 \mathrm{~g}$ and subsequent dilutions thereof in a saline diluent) for $20 \mathrm{~min}$ at $15^{\circ} \mathrm{C}$. After exposure, bacteria are separated from the sediment fraction by pressing a filter column into the exposure tube where they are then concentrated in the filtrate and subsequently aliquoted to a reading tube. The light output of all tubes (sediment-exposed and controls) is measured with a photometer, after which inhibition percentages can be calculated. 


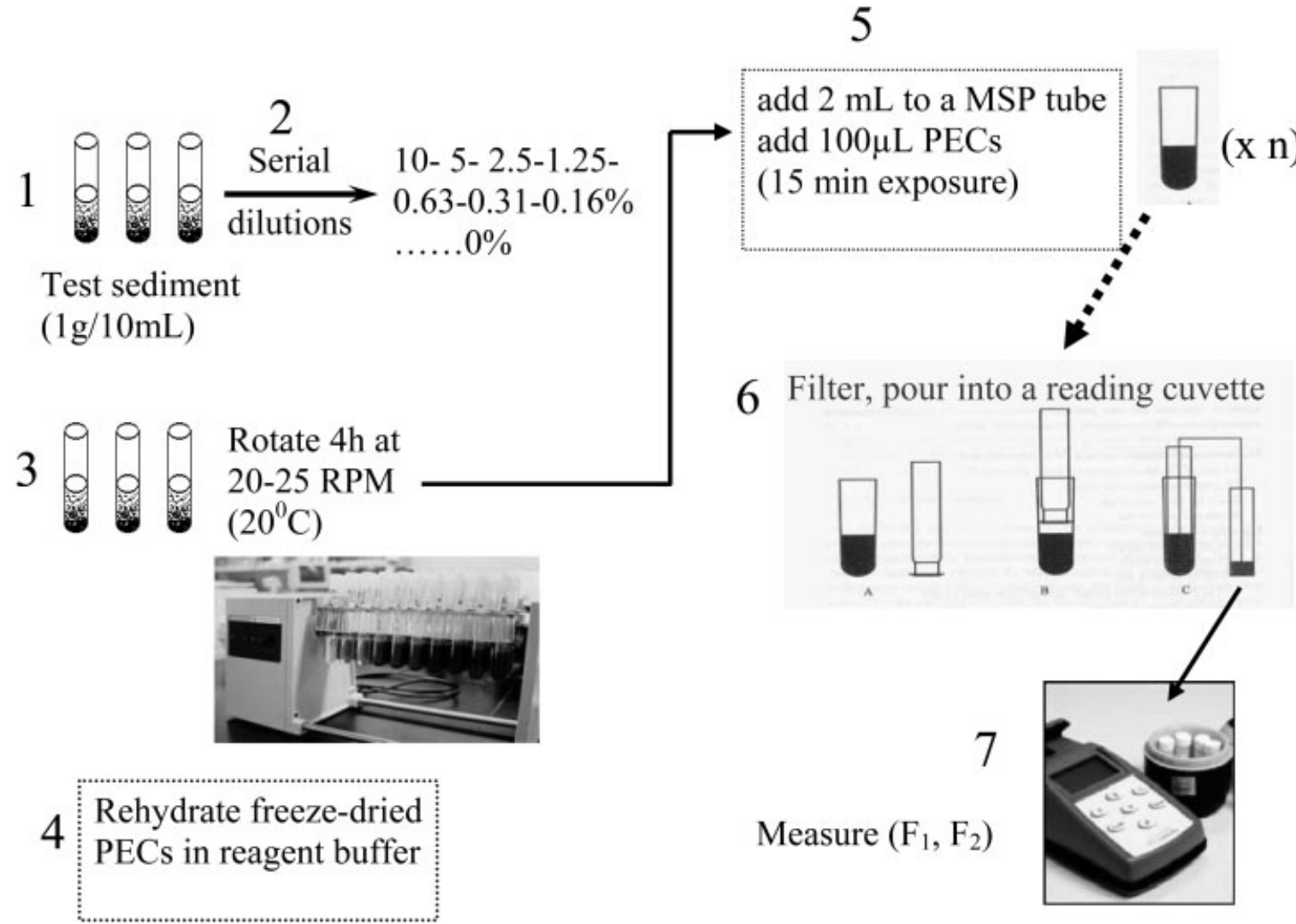

Fig. 1. Lum-SPA protocol developed with the LuminoTox Analyzer (refer to text in the Material and Methods section for details).

The determined endpoint is a 20 min $\mathrm{IC}_{50}$ (inhibitory concentration causing 50\% light loss) expressed in $\% \mathrm{wt} / \mathrm{v}$ ( $\mathrm{g}$ of wet or dry sediment per $100 \mathrm{~mL}$ of dilution water).

\section{LuminoTox Assay Principle}

The LuminoTox toxicity testing procedure makes use of stabilized photosynthetic enzyme complexes (PECs), isolated from spinach plant extracts. When PECs are challenged with chemicals or complex samples that can interfere with transmission of chlorophyll fluorescence linked to Photosystems I and II reaction sites, a corresponding decrease in fluorescence emission results (LuminoTox, 2005). The LuminoTox Analyzer, a special fluorometer programmed to measure photosynthetic activity based on production of chlorophyll fluorescence, can then measure the corresponding photosynthetic efficiency $\left(\Phi_{\mathrm{p}}\right)$ of exposed and unexposed PECs. The analyzer measures $\Phi_{\mathrm{p}}$ based on the following formula:

$$
\Phi_{\mathrm{p}}=\left(F_{2} \text { sample }-F_{1} \text { sample }\right) / F_{2} \text { blank }
$$

$F_{2}$ fluorescence relates to fully reduced plastoquinone $Q_{\mathrm{a}}$ after rapid application of a high light intensity excitation of the PECs by the instrument, whereas $F_{1}$ relates to fully oxidized $Q_{\text {a }}$ after corresponding application of a low light excitation to the PECs (LuminoTox, 2005). PEC fluorescence emissions for both $F_{1}$ and $F_{2}$ are measured at a wavelength $>700 \mathrm{~nm}$ after light excitation at $470 \mathrm{~nm}$. Percentages of inhibition based on exposure to different sample concentrations can then be calculated as follows:

$$
\% \text { inhibition }=\left[\left(\Phi_{\text {blank }}-\Phi_{\text {sample }}\right) / \Phi_{\text {blank }}\right] \times 100
$$

\section{LuminoTox Solid Phase (Lum-SPA) and LuminoTox Elutriate (Lum-ELU) Assays}

The experimental protocol developed for testing whole sediment toxicity with the LuminoTox Analyzer (LumSPA) is illustrated in Figure 1. A series of seven serial sediment dilutions $(10,5,2.5,1.25,0.63,0.31$, and $0.16 \%)$ and controls $(0 \%)$ were first prepared with Millipore Super Q water, in triplicate, in $20 \times 150 \mathrm{~mm}$ borosilicate glass tubes (steps 1 and 2). All tubes were then sealed with Parafilm and placed in a vertical rotator $\left(\mathrm{Caframo}^{\mathrm{TM}}\right.$ Reax 2 rotating mixer). Rotating speed was set at 20-25 rpm at room temperature $\left(20^{\circ} \mathrm{C} \pm 2^{\circ} \mathrm{C}\right)$ for $4 \mathrm{~h}$ (step 3). This mixing period is meant to maximize solubilization of hydrophilic contaminants (e.g. heavy metals), as well as of lower 
molecular weight hydrophobic chemicals (e.g. naphthalene, acenaphthene), and it may, in turn, better expose more strongly hydrophobic chemicals (e.g. three-ringed or more PAHs, PCBs) associated with the sediment for subsequent contact with PECs. Freeze-dried PECs are then rehydrated in reagent buffer (containing $50 \mathrm{mM}$ HEPES and $330 \mathrm{mM}$ sucrose at $\mathrm{pH} 7.5$ ) according to manufacturer's instructions (step 4) and allowed to stabilize for $15 \mathrm{~min}$ (LuminoTox, 2005). Immediately after vortexing individual glass tubes (starting with the $0 \%$ sediment-containing sediment tubes and ending with the $10 \%$ sediment tubes), a 2 mL-volume of control water ( $0 \%$ sediment) or of slurry (water-sediment mixture) is withdrawn from each tube and dispensed into a small plastic tube (identical to that used to perform the Mic-SPA). A $100 \mu \mathrm{L}$ volume of PECs is then pipetted into each plastic tube for a $15 \mathrm{~min}$ exposure period (step 5). Afterwards, PECs are easily separated from the sediment fraction by pressing a filter column (identical to that used to perform the Mic-SPA) into the exposure tube. The PECcontaining filtrate contents $(\sim 2 \mathrm{~mL})$ are next poured into a methyl acrylate (VWR Scientific Products, No. 58017-875) reading cuvette (step 6). Each cuvette is then placed into the LuminoTox Analyzer to obtain $F_{1}$ and $F_{2}$ readings, as well as photosynthetic efficiency $\left(\Phi_{\mathrm{p}}\right)$ and percentages of inhibition, as described before (step 7). The determined endpoint is a 15 min $\mathrm{IC}_{50}$ (inhibitory concentration causing a $50 \%$ fluorescence inhibition related to photosynthetic efficiency) expressed in \% of wet or dry sediment (g per $100 \mathrm{~mL}$ of dilution water).

The experimental protocol developed for testing sediment elutriate toxicity with the LuminoTox Analyzer (Lum-ELU) is performed with some variants as compared to Lum-SPA. A $25 \%(5 \mathrm{~g} / 20 \mathrm{~mL})$ sediment slurry is prepared, in triplicate, in $50 \mathrm{~mL}$ plastic tubes (Fisher Scientific, No. 14-961-33) with Millipore Super Q water. The three tubes were then capped and placed in a vertical rotator (Caframo $^{\mathrm{TM}}$ Reax 2 rotating mixer). Rotating speed was set at $20-25 \mathrm{rpm}$ at room temperature $\left(20^{\circ} \mathrm{C} \pm 2^{\circ} \mathrm{C}\right)$ for $4 \mathrm{~h}$. This mixing period is meant to maximize solubilization of hydrophilic contaminants (e.g. heavy metals), as well as of lower molecular weight hydrophobic chemicals (e.g. naphthalene and acenaphthene), for later contact of the elutriate with PECs. Afterwards, the three $50 \mathrm{~mL}$ tubes are centrifuged (3000 rpm, $10 \mathrm{~min}$ ) and a series of seven serial dilutions of each supernatant $(25,12.5,6.25,3.125,1.56,0.78$, and $0.39 \%$ ) and controls $(0 \%)$ are prepared in smaller tubes (any plastic or glass tube of $10-15 \mathrm{~mL}$ volume capacity is adequate for this purpose) with Millipore Super Q water as dilution medium. Contents of these tubes comprise the sediment elutriates from which $2 \mathrm{~mL}$ of each are then pipetted into another tube (e.g., Mic-SPA tubes) to which have just been added $100 \mu \mathrm{L}$ of (rehydrated and stabilized) PECs.

TABLE I. Toxicity data (and selected chemical data) for certified reference material (CRM) sediments related to Lum-SPA and Mic-SPA assays

\begin{tabular}{|c|c|c|c|c|}
\hline $\begin{array}{l}\text { CRM } \\
\text { Sediment }\end{array}$ & $\begin{array}{l}\text { Lum-SPA } \mathrm{IC}_{50}{ }^{\mathrm{a}} \\
(\% \text { in } \mathrm{g} / 100 \mathrm{~mL})\end{array}$ & $\begin{array}{l}\text { Mic-SPA } \mathrm{IC}_{50}{ }^{\mathrm{a}} \\
(\% \text { in } \mathrm{g} / 100 \mathrm{~mL})\end{array}$ & $\begin{array}{l}\text { PAHs }^{\mathrm{b}} \\
(\mu \mathrm{g} / \mathrm{g})\end{array}$ & $\begin{array}{c}\mathrm{Cu}^{\mathrm{c}} \\
(\mu \mathrm{g} / \mathrm{g})\end{array}$ \\
\hline \multicolumn{5}{|c|}{ CRM sediments mostly contaminated with organics (NWRI, 2000) } \\
\hline EC-1 & $0.77(0.66-0.91)$ & $0.065(0.057-0.073)$ & 92.6 & - \\
\hline $\mathrm{EC}-2$ & $1.14(0.99-1.31)$ & $0.22(0.18-0.27)$ & 20.1 & - \\
\hline $\mathrm{EC}-3$ & $1.26(1.07-1.50)$ & $0.67(0.59-0.75)$ & 3.47 & - \\
\hline $\mathrm{EC}-4$ & $0.58(0.53-0.63)$ & $0.052(0.022-0.12)$ & 6.74 & - \\
\hline EC-5 & $0.59(0.48-0.73)$ & $0.18(0.12-0.27)$ & 4.99 & - \\
\hline EC-6 & $1.65(1.37-2.02)$ & $0.75(0.65-0.86)$ & 1.97 & - \\
\hline $\mathrm{EC}-7^{\mathrm{d}}$ & $3.20(2.64-3.90)$ & $>19.7^{\mathrm{e}}$ & 1.23 & - \\
\hline EC-8 & $0.55(0.48-0.61)$ & $0.36(0.32-0.41)$ & 2.11 & - \\
\hline \multicolumn{5}{|c|}{ CRM sediments mostly contaminated with metals (NWRI, 2000) } \\
\hline SUD-1 & $0.41(0.34-0.51)$ & $0.072(0.02-0.28)$ & - & 565 \\
\hline HR-1 & $0.80(0.66-0.98)$ & $0.088(0.06-0.13)$ & - & 78.5 \\
\hline TH-1 & $0.52(0.44-0.61)$ & $0.073(0.05-0.11)$ & - & 103.2 \\
\hline TH-2 & $0.67(0.61-0.73)$ & $0.053(0.047-0.060)$ & - & 123 \\
\hline WQB-1 & $0.94(0.81-1.09)$ & $0.080(0.065-0.098)$ & - & 78.3 \\
\hline WQB-3 & $1.06(0.84-1.34)$ & $0.25(0.22-0.29)$ & - & 82.9 \\
\hline
\end{tabular}


Following a $15 \mathrm{~min}$ exposure period, the content of each tube is poured into a reading (methyl acrylate) cuvette. Each cuvette is then placed into the LuminoTox Analyzer to obtain $F_{1}$ and $F_{2}$ readings, as well as photosynthetic efficiency $\left(\Phi_{\mathrm{p}}\right)$ and percentages of inhibition, as described earlier. The determined endpoint is a 15 min $\mathrm{IC}_{20}$ (inhibitory concentration causing a $20 \%$ fluorescence inhibition related to photosynthetic efficiency) expressed in \% of wet or dry sediment elutriate prepared from a $25 \%$ sediment slurry (i.e., $5 \mathrm{~g}$ of sediment per $20 \mathrm{~mL}$ of dilution water).

\section{Data Analysis}

Mic-SPA $\mathrm{IC}_{50} \mathrm{~s}$ and $95 \%$ confidence limits were calculated by regression analysis with an $\mathrm{Omni}^{\mathrm{TM}}$ software package (Version 1.18 or equivalent) marketed by Strategic Diagnostics (USA). Lum-SPA and Lum-ELU measurement endpoints $\left(\mathrm{IC}_{20} \mathrm{~s}, \mathrm{IC}_{50} \mathrm{~s}\right.$, and $95 \%$ confidence limits) were calculated using a nonlinear regression procedure (REGTOX) that is available as an Excel macro at the following link: http://eric.vindimian.9online.fr. Correlation analysis between Mic-SPA and Lum-SPA or between any toxicity test and metal/organic contaminant data for the reference CRM sediments was determined using Pearson Product Moment or Spearman Rank Order tests with significance set at $P<$ 0.05 . Correlation analysis was performed with Statistica software (Version 5.5).

\section{RESULTS AND DISCUSSION}

\section{CRM Sediments}

Toxicity data generated with the Lum-SPA and Mic-SPA assays are shown in Table I. Of the 14 CRM sediment samples, only EC-7 failed to yield a reportable $\mathrm{IC}_{50}$ value with the Mic-SPA assay. This same CRM sediment yielded the highest Lum-SPA $\mathrm{IC}_{50}$ value and is also characterized by the lowest content in total PAHs. A significant correlation $(P<0.05)$ was shown to exist between Lum-SPA and MicSPA $\mathrm{IC}_{50}$ s (Fig. 2), indicating that both tests display a similar toxicity response pattern for a group of CRM sediments $(n=13)$ having differing contaminant profiles (NWRI, 2000). Additional analyses (correlation data not shown) also demonstrated marginally significant correlations between Lum-SPA with $\mathrm{Cu}(r=-0.77 ; P=0.072)$, and also between Mic-SPA with $\mathrm{Cu}(r=-0.71 ; P=0.10)$ for the group of CRM sediments mostly contaminated with metals (see Table I), as well as significant correlations between MicSPA and total PAHs $(r=-0.86 ; P=0.002)$ for the remaining eight CRM sediments mostly contaminated with organics (see Table I), suggesting that these two solid phase assays can respond differently to (in)organic classes of contaminants. No other significant correlation was found for this group of eight CRM sediments between either Lum-SPA and total PCBs or chlorobenzenes or between Mic-SPA and these same classes of chemicals.

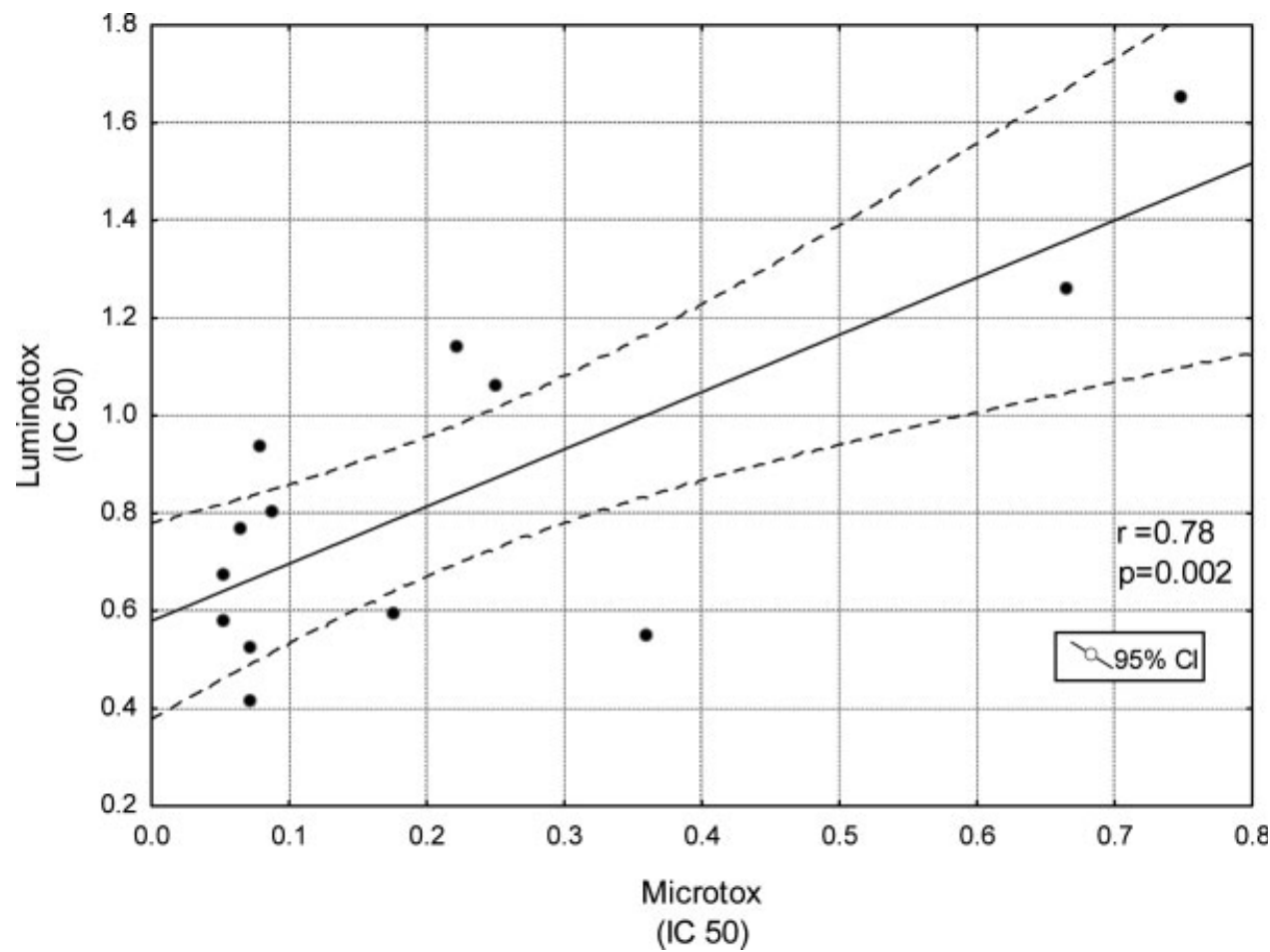

Fig. 2. Correlation analysis for Lum-SPA and Mic-SPA $I C_{50}$ S after testing $13 \mathrm{CRM}$ sediments. Endpoints are expressed in \% wt/v ( $g$ of dry sediment per $100 \mathrm{~mL}$ of dilution water). 
TABLE II. Toxicity data generated for certified reference material (CRM) sediment elutriates with the Lum-ELU assay

\begin{tabular}{lclc}
\hline $\begin{array}{l}\text { CRM-org } \\
\text { Sediments }^{\mathrm{a}}\end{array}$ & $\begin{array}{c}\text { Lum-ELU } \\
\mathrm{IC}_{20}{ }^{\mathrm{b}}\end{array}$ & $\begin{array}{c}\text { CRM-Met } \\
\text { Sediments }^{\mathrm{c}}\end{array}$ & $\begin{array}{c}\text { Lum-ELU } \\
\mathrm{IC}_{20}{ }^{\mathrm{b}}\end{array}$ \\
\hline EC-1 & $51.1(35.7-68.0)^{\mathrm{d}}$ & SUD-1 & $0.75(0.61-0.93)^{\mathrm{d}}$ \\
EC-2 & $91.6(70.9-95.1)^{\mathrm{d}}$ & HR-1 & $>100$ \\
EC-3 & $>100$ & TH-1 & $49.4(32.3-79.8)^{\mathrm{d}}$ \\
EC-4 & $>100$ & TH-2 & $80.6(65.1-95.2)^{\mathrm{d}}$ \\
EC-5 & $>100$ & WQB-1 & $52.8(37.3-70.1)^{\mathrm{d}}$ \\
EC-6 & $>100$ & WQB-3 & $51(41.8-60.1)^{\mathrm{d}}$ \\
EC-7 & $>100$ & & \\
EC-8 & $4.67(2.05-9.8)^{\mathrm{d}}$ & & \\
\hline
\end{tabular}

${ }^{a}$ CRM sediments mostly contaminated with organics (NWRI, 2000).

${ }^{\mathrm{b}} 15 \mathrm{~min} \mathrm{IC}_{20}$ (inhibitory concentration causing a $20 \%$ fluorescence inhibition related to photosynthetic efficiency) expressed in \% of dry sediment elutriate prepared from a $25 \%$ sediment slurry (i.e., $5 \mathrm{~g}$ of sediment per $20 \mathrm{~mL}$ of dilution water).

${ }^{\mathrm{c}} \mathrm{CRM}$ sediments mostly contaminated with metals (NWRI, 2000).

${ }^{\mathrm{d}} \mathrm{IC}_{20}$ values with their $95 \%$ confidence intervals (in brackets).

Because LuminoTox testing on CRM sediment elutriates revealed few 50\% inhibitory effects on PEC photosynthetic efficiency, we chose to report these responses via an $\mathrm{IC}_{20}$ to reduce the number of indeterminate toxicity values (i.e. $\left.\mathrm{IC}_{50}>100 \%\right)$. With this more sensitive endpoint, the LumELU assay displayed toxicity responses (i.e. measurable $\mathrm{IC}_{20} \mathrm{~s}$ ) for eight of the $14 \mathrm{CRM}$ sediments (Table II), suggesting that it is capable of determining the presence of sediment contaminants that are readily soluble in an aqueous elutriate. Three of 8 elutriates and five of 6 elutriates, prepared from CRM sediments mostly contaminated with organics (CRM-org sediments) and metals (CRM-met sediments), respectively, were shown to be toxic (Table II). Lesser "toxicity hits" obtained on the CRM-org sediment elutriates is not altogether surprising, since they are mainly contaminated with classes of hydrophobic chemicals (e.g. PAHs and PCBs) that do not easily become soluble in an aqueous medium. Indeed, no significant correlation was found between Lum-ELU $\mathrm{IC}_{20}$ s and total PAHs, total PCBs or chlorobenzenes for these eight CRM-org sediments (indeterminate $\mathrm{IC}_{20}$ values of " $>100$ " in Table II were set at "100" for the purpose of this correlation analysis). In contrast and based on available CRM sediment metal data (NWRI, 2000), correlations were demonstrated between Lum-ELU $\mathrm{IC}_{20}$ s and As $(r=-0.77 ; P=0.1$, marginally significant), between Lum-ELU and $\mathrm{Cu}(r=-0.997 ; P=$ 0.001), and between Lum-ELU and Ni $(r=-0.997 ; P=$ 0.001) for the six CRM-met sediments. This again suggests that Lum-ELU testing is capable of detecting the toxicity of metals that are loosely adsorbed to these sediments. Of the six CRM-met sediments, HR-1 is the least contaminated in $\mathrm{As}, \mathrm{Cu}$, and Ni (NWRI, 2000), which may explain the nontoxic response of the Lum-ELU assay towards its elutriate.

\section{Natural Freshwater Sediments}

The Lum-SPA and Mic-SPA bioassays were further conducted on 12 sediments originating from lotic and lentic freshwater environments of Canada and Germany (see Materials and Methods section). As with the CRM sediments, their toxicity responses were again significantly correlated, suggesting that both tests answer to (at least some of) the same types of contaminants likely present in these sediments (Fig. 3). At this time, absence of information on the physicochemical makeup of these sediments (e.g., combined presence of natural and anthropogenic contaminants, grain size) precludes further interpretation. Sediment samples M3 and M4 (Fig. 3), likely influenced by municipal effluents because of the area in the Saint-Lawrence River where they were collected, exceptionally demonstrate that Lum-SPA and Mic-SPA toxicity responses are linked to different factors. Removing these from the correlation analysis would have resulted in an even better agreement between the two assays.

\section{Influence of Sediment Grain Size on Lum-SPA Toxicity Responses}

Test sediment grain size has been shown to be an important confounding factor interfering with toxicity responses in solid phase assays conducted with luminescent bacteria (Environment Canada, 2002). With the Mic-SPA assay, decreasing grain size causes a pronounced decrease in $\mathrm{IC}_{50} \mathrm{~s}$ (increased toxicity) when fines, defined as sediment

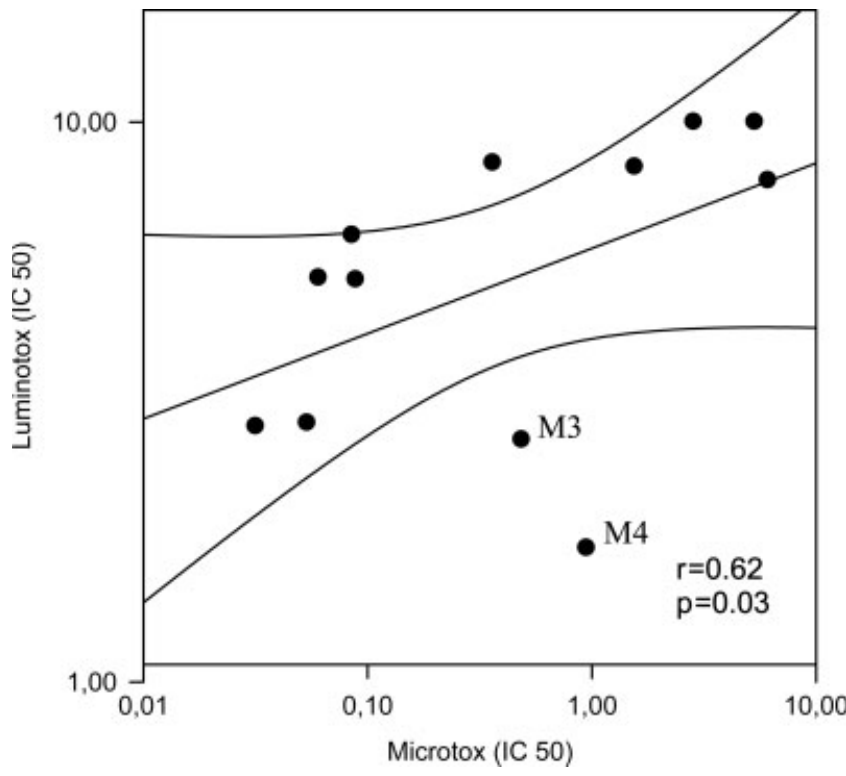

Fig. 3. Correlation analysis for Lum-SPA and Mic-SPA $\mathrm{IC}_{50} \mathrm{~S}$ after testing 12 natural freshwater sediments. Endpoints are expressed in \% $\mathrm{wt} / \mathrm{v}$ ( $\mathrm{g}$ of wet sediment per $100 \mathrm{~mL}$ of dilution water). 
TABLE III. Influence of sediment grain size on Lum-SPA assay toxicity responses

\begin{tabular}{|c|c|c|c|}
\hline \multicolumn{2}{|c|}{ Experimental Mixture } & \multirow[b]{2}{*}{$\mathrm{IC}_{50}$} & \multirow{2}{*}{$\begin{array}{l}95 \% \text { Confidence } \\
\text { Intervals }\end{array}$} \\
\hline Kaolin $(\%)$ & Silica Sand (\%) & & \\
\hline 0 & 100 & 20.5 & $11.0-53.7$ \\
\hline 5 & 95 & 14.0 & $11.0-23.1$ \\
\hline 10 & 90 & 13.7 & $10.3-20.9$ \\
\hline 20 & 80 & 4.7 & $3.8-6.4$ \\
\hline 40 & 60 & 4.0 & $2.6-5.9$ \\
\hline 60 & 40 & 3.1 & $2.3-3.9$ \\
\hline 80 & 20 & 3.0 & $2.6-3.5$ \\
\hline 90 & 10 & 2.2 & $1.9-2.4$ \\
\hline 95 & 5 & 3.7 & $3.3-4.1$ \\
\hline 100 & 0 & 2.4 & $1.9-4.3$ \\
\hline
\end{tabular}

$\mathrm{IC}_{50} \mathrm{~s}$ are expressed in $\% \mathrm{wt} / \mathrm{v}$ (g of dry sediment per $100 \mathrm{~mL}$ of dilution water).

particles $\leq 0.063 \mathrm{~mm}$ in size, increase within the sediment matrix (Ringwood et al., 1997; Tay et al., 1998). Indeed, Mic-SPA assays undertaken with $100 \%$ (uncontaminated) kaolin clay, where sediment particles are $<0.004 \mathrm{~mm}$ in size, have been found to produce $\mathrm{IC}_{50} \mathrm{~s}$ ranging from 0.14 to $0.245 \%$ (Ringwood et al., 1997; Tay et al., 1998). These studies have prompted the establishment of guidelines to confirm the toxicity of sediment samples assessed by MicSPA assays, one of which is to consider toxic any sediment with an $\mathrm{IC}_{50}<0.1 \%$, regardless of grain size (Environment Canada, 2002).

In this work, we conducted an analogous kaolin clay toxicity experiment with the Lum-SPA assay to ascertain whether its toxicity responses could also be subject to the influence of fines. In a manner similar to that of the MicSPA assay, Lum-SPA $\mathrm{IC}_{50}$ s displayed a sharp drop when the percentage of fines increased to $20 \%$ or more (Table III). At such concentrations of fines, $\mathrm{IC}_{50} \mathrm{~s}$ ranged from 2.17 to $4.72 \%$. These results suggest that sediment samples appraised with the Lum-SPA protocol should only be considered toxic when their $\mathrm{IC}_{50} \mathrm{~S}$ are less than $2 \%$, especially if sediment grain size has not been determined. Since CRM sediments were "ground to less than 200-mesh particle size" (NWRI, 2000), which corresponds to $<0.074 \mathrm{~mm}$, they can be considered as "fines" (as defined previously). Hence, based on a cut-off sediment toxicity criterion of $<0.1 \%$ and $<2 \%$ for Mic-SPA and Lum-SPA $\mathrm{IC}_{50}$ s, respectively, seven of 14 CRM sediments would be considered toxic owing to the presence of (in)organic contaminants according to the former assay, whereas 13 of 14 would be likewise considered according to the latter (Table I). Interpretation regarding the intrinsic toxicity of the 12 natural freshwater samples, based on Lum-SPA and Mic-SPA assays (Fig. 3), is presently not possible because grain size sediment data are not yet available. The generally higher $\mathrm{IC}_{50}$ values observed, ranging from $1.7 \%$ (sample M-4) to $8.3 \%$ (sample M-2) for the Lum-SPA assay $\left(\mathrm{IC}_{50}\right.$ data not shown but linked to Fig. 3 ), suggest that most of these natural sediments have coarser grain sizes and that the above toxicity criterion of $<2 \%$ for Lum-SPA would not apply.

Clearly, further studies will be required to more fully understand the relationship between LuminoTox solid phase responses and the physicochemical makeup of sediments (e.g., grain size, combined presence of natural and anthropogenic contaminants). Awareness of confounding factors will then allow application of specific guidelines for proper interpretation of test data that will adequately distinguish between natural and anthropogenic sediment toxicity. At this time, the preliminary results obtained with the LumSPA and Lum-ELU protocols intimate that LuminoTox technology appears to hold promise for screening the toxic potential of solid media.

The first two authors thank the Brazilian government for a CAPES (Coordenaçao de Aperfeiçoamento de Pessoal de Nivel Superior) grant that allowed the first author to undertake a stay (November 2004 to April 2005) in the Saint-Lawrence Centre to contribute to this study as part of her doctorate thesis. Other authors thank their respective managements (Centre Saint-Laurent, CSIR, Université de Nantes) for supporting this applied research project.

\section{REFERENCES}

Adams MS, Stauber JL. 2004. Development of a whole-sediment toxicity test using a benthic marine microalga. Environ Toxicol Chem 23:1957-1968.

Bitton G, Garland E, Kong IC, Morel JL, Koopman B. 1996. A direct solid phase assay for heavy metal toxicity. I. Methodology. J Soil Contam 5:385-394.

Blaise C, Ménard L. 1998. A micro-algal solid phase test to assess the toxic potential of freshwater sediments. Water Qual Res J Canada 33:133-151.

Borgmann U, Norwood WP, Nowierski M. 2005. Amphipod (Hyalella azteca) solid-phase toxicity test using high watersediment ratios. In: Blaise C, Férard JF, editors. Small-Scale Freshwater Toxicity Investigations, Vol. 1. Dordrecht, The Netherlands: Springer. pp 413-436.

Boucher N, Lorrain L, Rouette ME, Perron E, Déziel N, Tessier L, Bellemare F. 2005. Rapid Testing of Toxic Chemicals. American Laboratory. Vol. 37, Number 6. Shelton, CT, USA: International Scientific Communications, Inc. pp 34-37.

Corbisier P, Thiry E, Diels L. 1996. Bacterial biosensors for the toxicity assessment of solid wastes. Environ Toxicol Water Qual 11:171-177.

Côté C, Blaise C, Schroeder J, Douville M, Michaud JR. 1998. Investigating the adequacy of selected micro-scale bioassays to predict the toxic potential of freshwater sediments through a tier process. Water Qual Res J Canada 33:253-277.

Doe K, Jackman P, Scroggins R, McLeay D, Wohlgeschaffen G. 2005. Solid-phase test for sediment toxicity using the luminescent bacterium, Vibrio fischeri. In: Blaise C, Férard JF, editors. 
Small-Scale Freshwater Toxicity Investigations, Vol. 1. Dordrecht, The Netherlands: Springer. pp 107-136.

Environment Canada. 2002. Biological test method: Solid-phase reference method for determining the toxicity of sediment using luminescent bacteria (Vibrio fischeri). Environment Canada, Montreal, Quebec.Environmental Protection Series, EPS $1 / \mathrm{RM} / 42$

Environment Canada. 2005. LuminoTox: a tool for rapid toxicity testing. Technological innovation data sheet. Environment Canada, Montreal, Quebec. ISBN 0-662-39710-X.

Kwan KK, Dutka BJ. 1995. Comparative assessment of two solidphase toxicity bioassays: The direct sediment toxicity testing procedure (DSTTP) and the Microtox ${ }^{\mathbb{R}}$ solid phase test (SPT). Bull Environ Contam Toxicol 55:338-346.

LuminoTox. 2005. LuminoTox Analyser: Owner's Manual. Shawinigan, Quebec, Canada: Lab_Bell, Inc. 19 p.
NWRI (National Water Research Institute). 2000. Certified reference materials and quality assurance services, 2002/2001 Catalogue, Version 4. NWRI, Environment Canada, Burlington, Ontario, Canada. 26 p.

Péry ARR, Mons R, Garric J. 2005. Chironomus riparius solidphase assay. In: Blaise C, Férard JF, editors. Small-Scale Freshwater Toxicity Investigations, Vol. 1. Dordrecht, The Netherlands: Springer. pp 437-451.

Ringwood AH, Delorenzo ME, Ross PE, Holland AF. 1997. Interpretation of Microtox solid phase toxicity tests: The effects of sediment composition. Environ Toxicol Chem 16:1135-1140.

Tay KL, Doe KG, MacDonald AJ, Lee K. 1998. The influence of particle size, ammonia, and sulphide on toxicity of dredged materials for ocean disposal. In: Wells PG, Lee K, Blaise C, editors. Microscale Testing in Aquatic Toxicology-Advances, Techniques and Practice. New York, NY: CRC Press. pp 559-574. 